\title{
Kajian Sistem Drainase di Daerah Jalan Pemuda, Kota Bogor
}

\author{
(Study of the Drainage System in Pemuda Street, Bogor City)
}

\author{
Titon Sadewa ${ }^{1}$, Sutoyo $^{1 *}$ \\ ${ }^{1}$ Departemen Teknik Sipil dan Lingkungan, Fakultas Teknologi Pertanian, Institut Pertanian Bogor. \\ Jl. Raya Dramaga, Kampus IPB Dramaga, PO BOX 220, Bogor, Jawa Barat Indonesia \\ *Penulis korespondensi: sutoyo@apps.ipb.ac.id
}

Diterima: 01 November 2018

Disetujui: 22 Desember 2018

\begin{abstract}
Flood was a problem that often occurs in the big cities of Indonesia. High rainfall, increasing population and unappropriate urban drainage system were the factors that cause the flood problems. The purpose of the research were to identify the condition of the existing drainage channels and to analyze the amount of runoff and comparing the run off to drainage channels in Pemuda Street. The analysis was carried out with simulations using EPA SWMM 5.1. Based on field observations, the drainage system in Pemuda Street was quite good with a rectangular cross section and were constructed using concrete. Based on the simulation results, the peak discharge runoff were around $0.017-2.119 \mathrm{~m}^{3} / \mathrm{s}$, and water flow in channels C5, C40, and C49 almost meet the channel capacity with a discharge of $1.49 \mathrm{~m}^{3} / \mathrm{s}, 0.46 \mathrm{~m}^{3} / \mathrm{s}$, and 0.23 $\mathrm{m}^{3} / \mathrm{s}$ respectively and would be potential to become flood. To reduce the flooding potential at Pemuda Street, dimension changes were needed on C5 and C49 channels with the final dimensions of $1.02 \mathrm{mx}$ $0.77 \mathrm{~m}$ and $0.5 \mathrm{~m} \times 0.59 \mathrm{~m}$. But, because of the C5 dimension was changed, so waterflow in C40 were appropriate with channel capacity and would not need dimension change.
\end{abstract}

Key words: drainage, EPA SWMM 5.1, rainfall, runoff

\section{PENDAHULUAN}

Banjir merupakan salah satu masalah yang sering terjadi di Indonesia, khususnya pada musim hujan. Permasalahan ini hampir setiap tahun berulang, bahkan cenderung mengalami peningkatan dari segi frekuensi, luasan, kedalaman, dan durasi. Jika dilihat ke belakang, akar permasalahan banjir di perkotaan berawal dari pertambahan penduduk yang sangat besar di atas rata rata pertumbuhan nasional akibat urbanisasi. Pertambahan penduduk ini tidak diimbangi dengan penyediaan sarana dan prasarana perkotaan yang memadai sehingga morfologi kota menjadi tidak teratur. Banjir terjadi akibat tidak berfungsinya drainase sebagai saluran untuk menyalurkan kelebihan air. Pemanfaatan lahan yang tidak tertib turut menyebabkan persoalan drainase di perkotaan menjadi sangat kompleks. Selain karena masalah sedimentasi, kondisi saluran yang rusak juga menjadi salah satu penyebab terjadinya genangan (Luciana et al. 2013). Menurut Wibowo et al. (2014) penyebab utama terjadinya banjir atau genangan air adalah adanya perubahan dari lanskap alami menjadi lahan terbangun dalam wujud jalan, area parkir, trotoar, dan gedung perkantoran, sehingga meningkatkan permukaan yang kedap air. Eratnya kaitan antara banjir dan sistem drainase menjadikan drainase penting untuk dikaji sebagai salah satu upaya bagi penanggulangan masalah banjir.

Menurut Dewi et al. (2014), drainase merupakan sarana atau prasarana untuk mengalirkan air hujan dari suatu tempat ke tempat lain. Alasan pemilihan 
kawasan ini sebagai lokasi penelitian adalah karena dalam kurun waktu lima tahun kawasan tersebut mengalami banjir setiap kali hujan deras melanda wilayah kota Bogor. Disisi lain, di daerah Jalan Pemuda, Kota Bogor terdapat fasilitas publik yaitu Gedung Olahraga (GOR) Padjajaran, dan Taman Heulang, SMPN 5 Bogor, kemudian instansi pemerintahan yaitu Badan Penyelenggara Jaminan Sosial (BPJS) Ketenagakerjaan, Balai Pengujian Mutu dan Sertifikasi, Dinas Pendapatan Daerah Kota Bogor, Dinas Pekerjaan Umum dan Penataan Ruang Kota Bogor, Dinas Bina Marga dan Sumber Daya Air, Dinas Perindustrian dan Perdagangan Kota Bogor, dan Kantor Pelayanan Pajak Pratama Ciawi, serta kawasan pemukiman. Oleh karena itu, perlu dilakukan evaluasi kondisi saluran drainase di daerah Jalan Pemuda Kota Bogor dengan melihat kesesuaian saluran drainase ditinjau dari curah hujan yang terjadi beberapa tahun sebelumnya.

Tujuan penelitian ini adalah mengidentifikasi dan menganalisis saluran drainase yang ada di kawasan sekitar Jalan Pemuda, Kota Bogor serta menganalisis besaran limpasan yang terjadi dan mengevaluasi kesesuaiannya dengan jaringan drainase yang ada menggunakan EPA SWMM 5.1. Manfaat dari penelitian ini adalah sebagai rekomendasi bagi Pemerintah Daerah (Pemda) Bogor untuk perbaikan sistem drainase di kawasan Jalan Pemuda, Kota Bogor.

\section{METODOLOGI}

Penelitian ini dilaksanakan mulai April hingga Juni 2018. Pengambilan data primer dilakukan pada lokasi penelitian, yaitu Jalan Pemuda Kota Bogor Jawa Barat. Gambar lokasi penelitian dapat dilihat pada Gambar 1. Langkah - langkah yang dilakukan pada penelitian ini diawali dengan melakukan pendefinisian masalah dan studi literatur untuk menentukan tujuan akhir dari penelitian yang dilakukan serta untuk memperoleh dasar teori yang dibutuhkan. Kegiatan penelitian ini mencakup pengumpulan data, pengolahan data, analisis data, serta pengambilan kesimpulan. Penelitian mengenai analisis kapasitas saluran drainase memerlukan data primer berupa dimensi dan elevasi saluran serta luas subcatchment, dan data sekunder berupa data curah hujan harian maksimum tahun 2007-2016 yang diperoleh dari BMKG, peta tutupan lahan, dan topografi. data primer dan sekunder yang telah terkumpul kemudian diolah.

Pengolahan data dimulai dengan menentukan nilai curah hujan rencana serta daerah pervious dan impervious menggunakan data sekunder yang telah didapatkan. Identifikasi daerah pervious dilakukan dengan melakukan validasi lapang di lapangan untuk melihat daerah yang dapat menyerap air melalui infiltrasi (pervious) dan daerah yang tidak dapat melewatkan air (impervious). Kemudian dapat dihitung persentase luas daerah pervious dan impervious untuk setiap subcatchment, sebagai input data dalam subcatchment. Curah hujan rencana adalah curah hujan terbesar yang mungkin terjadi disuatu daerah pada periode ulang tertentu yang dipakai sebagai dasar perhitungan perencanaan suatu bangunan (Krisnayanti et al. 2017). Analisis frekuensi untuk mendapatkan nilai curah hujan rencana dilakukan dengan menggunakan teori probability distribution, antara lain Distribusi Normal, Distribusi Log Normal, Distribusi Log Person III dan Distribusi Gumbel. Selanjutnya untuk penentuan jenis distribusi yang digunakan akan dilakukan uji kecocokan berdasarkan Uji Chi Kuadrat. Bentuk distribusi chi kuadrat tergantung dari derajat bebas (Db) (Isfandari dan Reini 2014). Data yang diperoleh kemudian diolah menggunakan pemodelan EPA SWMM 5.1. 
Langkah awal dalam penggunaan SWMM adalah pembagian subcatchment pada area penelitian. Pembagian tersebut sesuai dengan daerah tangkapan air (DTA) yang ditentukan berdasarkan pada elevasi lahan dan pergerakan limpasan ketika terjadi hujan. Pembuatan model jaringan dilakukan berdasarkan sistem jaringan drainase yang ada di lapangan.
Model jaringan ini terdiri dari subcatchment, node junction, conduit, outfall node, dan rain gage. Setelah model jaringan, selanjutnya dimasukkan semua nilai parameter yang dibutuhkan. Simulasi dapat dikatakan berhasil jika continuity error < 10\%. Dalam simulasi SWMM besarnya debit banjir dihitung dengan cara memodelkan suatu sistem drainase.

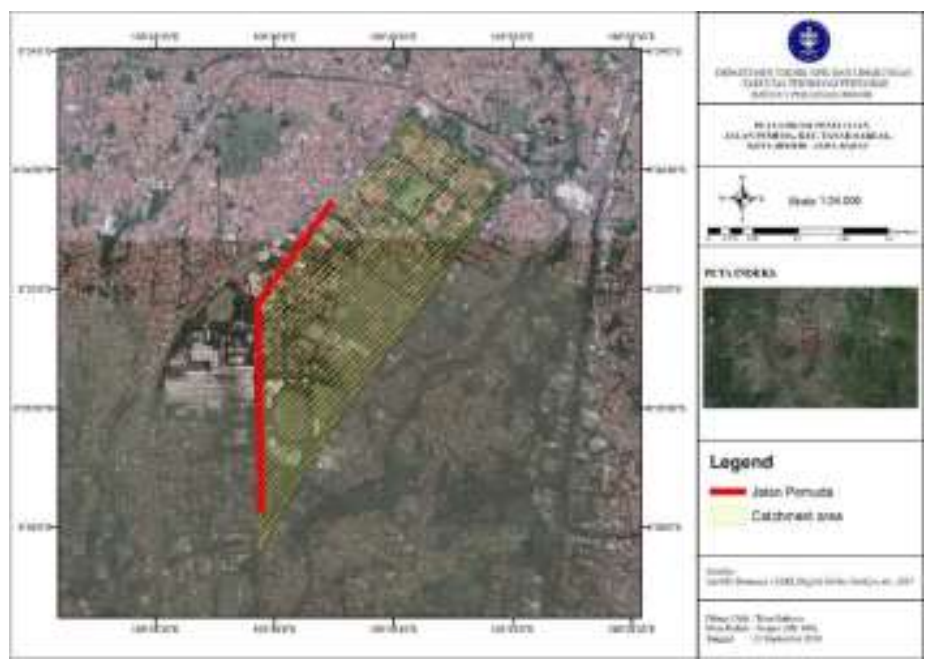

Gambar 1 Peta lokasi penelitian

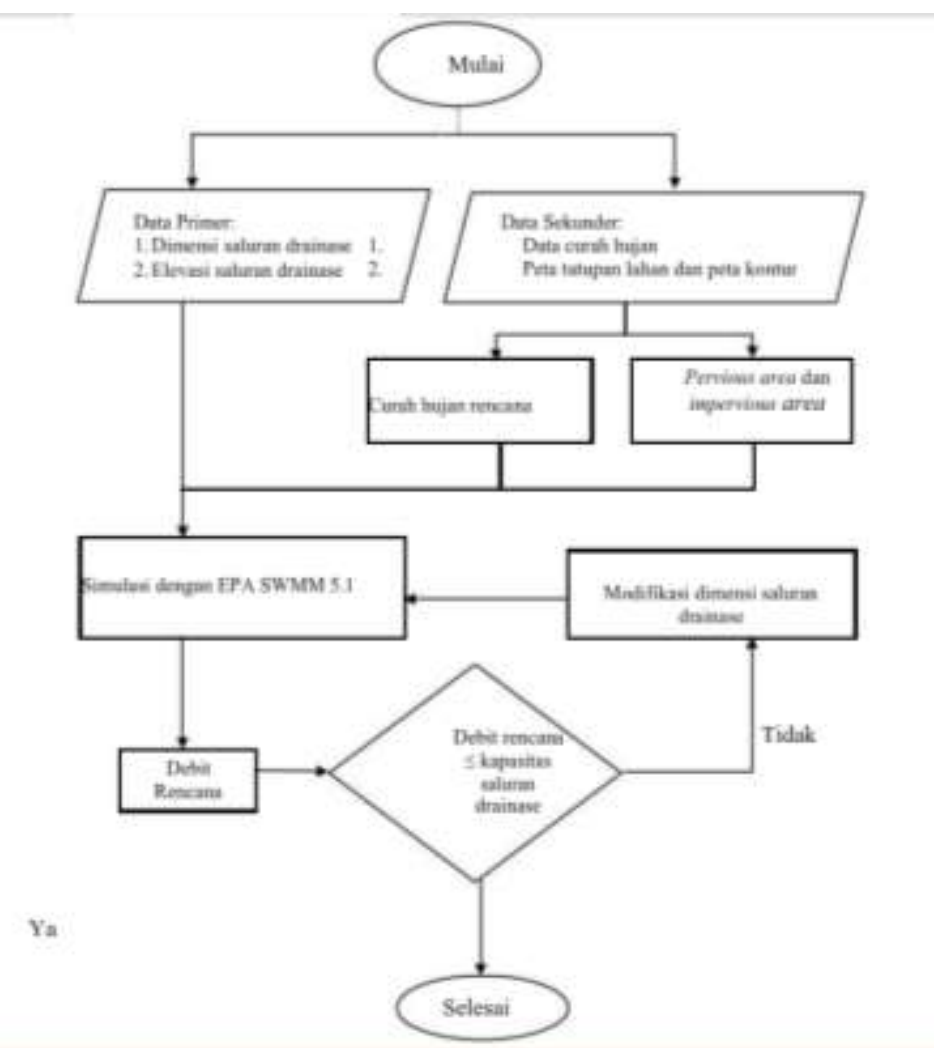

Gambar 2 Bagan alir penelitian 


\section{HASIL DAN PEMBAHASAN}

\section{Keadaan Umum Lokasi Penelitian}

Penelitian berada di daerah Jalan

Pemuda, Kecamatan Tanah Sareal, Kota

Bogor. Luas keseluruhan catchment area sistem drainase Jalan Pemuda, Kota Bogor sebesar \pm 65 ha dengan elevasi $194-230$ mdpl. Tata guna lahan pada lokasi penelitian didominasi bangunan perumahan, gedung perkantoran, gedung pemerintahan, dan insfrastruktur fasilitas umum, dengan perkerasan jalan aspal.

\section{Analisis Curah Hujan Rencana}

Analisis dilakukan dengan menggunakan data curah hujan harian dari tahun 2007 hingga 2016 milik Stasiun Badan Meteorologi, Klimatologi, dan Geofisika (BMKG). Curah hujan rencana dihitung berdasarkan data curah hujan harian maksimum selama 10 tahun yang dapat dilihat pada Tabel 1 .

Tabel 1 Data curah hujan harian maksimum 10 tahun

\begin{tabular}{|r|r|r|r|}
\hline Tahun & $\begin{array}{c}\text { Curah } \\
\text { Hujan } \\
\text { Maksimum } \\
(\mathrm{mm})\end{array}$ & Tahun & $\begin{array}{c}\text { Curah } \\
\text { Hujan } \\
\text { Maksimum } \\
\text { (mm) }\end{array}$ \\
\hline 2007 & 155.5 & 2012 & 116 \\
2008 & 104.5 & 2013 & 97.4 \\
2009 & 115.1 & 2014 & 169.1 \\
2010 & 144.5 & 2015 & 155.8 \\
2011 & 97.6 & 2016 & 108.6 \\
\hline
\end{tabular}

Perkiraan hujan rancangan didapatkan dari analisis frekuensi dengan kemungkinan tertinggi pada periode tertentu. Hasil analisis frekuensi berfungsi sebagai dasar perhitungan untuk mengantisipasi setiap kemungkinan yang akan terjadi. Menurut Widodo dan Ningrum (2015), data hidrologi yang diperlukan dalam perancangan drainase adalah data curah hujan dari stasiun pencatat curah hujan di sekitar atau terdekat lokasi studi. Analisis frekuensi dapat dilakukan dengan metoda probability distribution antara lain Distribusi Normal, Distribusi Log Normal, Distribusi Log-Person III, dan Distribusi Gumbel (Triatmodjo 2010). Kala ulang yang digunakan untuk menghitung nilai hujan rencana yaitu $2,5,10,25$, dan 50 tahun. Hasil analisis frekuensi curah hujan rencana dapat dilihat pada Tabel 2.

Tabel 2 Hasil analisis curah hujan rencana

\begin{tabular}{|c|c|c|c|c|}
\hline \multirow{4}{*}{$\begin{array}{l}\text { PUH } \\
\text { (tahun) }\end{array}$} & \multicolumn{4}{|c|}{ Curah Hujan Rencana (mm) } \\
\hline & \multirow[b]{3}{*}{ Normal } & \multirow{3}{*}{$\begin{array}{l}\text { Log } \\
\text { Normal }\end{array}$} & \multirow{2}{*}{$\begin{array}{l}\text { Log } \\
\text { Pearson }\end{array}$} & \multirow[b]{3}{*}{ Gumbel } \\
\hline & & & & \\
\hline & & & III & \\
\hline 2 & 126.41 & 123.9 & 122.49 & 122.76 \\
\hline 5 & 149.09 & 147.76 & 147.19 & 155 \\
\hline 10 & 160.98 & 162.03 & 63.1 & 176.35 \\
\hline 25 & 172.59 & 177.32 & 182.92 & 203.32 \\
\hline 50 & 181.78 & 190.42 & 199.24 & 223.33 \\
\hline
\end{tabular}

Hasil perhitungan nilai curah hujan rencana dari setiap metode memiliki nilai yang berbeda sehingga harus diuji kesesuaiannya dengan sifat masingmasing jenis distribusi. Hal ini dilakukan dengan melakukan tinjauan terhadap syarat batas parameter statistik tiap distribusi. Penentuan tipe distribusi dapat dilihat dari parameter-parameter statistik data pengamatan lapangan, yaitu nilai Cs dan Ck. Perbandingan parameter distribusi probabilitas dapat dilihat pada Tabel 3.

Tabel 3 Perbandingan parameter distribusi probabilitas

\begin{tabular}{|l|c|c|l|l|}
\hline \multirow{2}{*}{$\begin{array}{c}\text { Jenis } \\
\text { distribusi }\end{array}$} & Cs & Ck & \multicolumn{2}{c|}{ Syarat } \\
\cline { 4 - 5 } & & & $C s$ & $C k$ \\
\hline Gumbel & 0.47 & 2.4787 & $C s=1.14$ & $C k=5.4$ \\
\hline Normal & 0.47 & 2.4787 & $C s \approx 0$ & $C k \approx 3$ \\
\hline Log normal & 0.47 & 2.4787 & $C s=0.43$ & $C k=3.33$ \\
\hline Log pearson II & 0.47 & 2.4787 & \multicolumn{2}{|c|}{ selain dari nilai di atas } \\
\hline
\end{tabular}

Data pada Tabel 3 menunjukkan bahwa jenis distribusi Log pearson III memenuhi syarat. Jenis distribusi Log Pearson III selanjutnya dilakukan uji 
kecocokan dengan uji Chi Kuadrat. Uji kecocokan dimaksudkan untuk mengetahui apakah pemilihan metode distribusi frekuensi yang digunakan dapat diterima atau ditolak. Nilai distribusi yang digunakan untuk pengujian Chi Kuadrat yaitu distribusi Log Pearson III. Hasil pengujian dapat dilihat pada Tabel 4.

Tabel 4 Hasil perhitungan uji Chi Kuadrat distribusi Log Person III

\begin{tabular}{|r|l|r|r|r|r|r|}
\hline Kelas & Interval & Oi & Ei & Oi-Ei & (Oi-Ei)2 & (Oi-Ei)2/Ei \\
\hline 1 & $88.4375-106.3625$ & 3 & 2 & 1 & 1 & 0.5 \\
\hline 2 & $106.3625-124.2875$ & 3 & 2 & 1 & 1 & 0.5 \\
\hline 3 & $124.2875-142.2125$ & 0 & 2 & -2 & 4 & 2 \\
\hline 4 & $142.2125-160.1375$ & 3 & 2 & 1 & 1 & 0.5 \\
\hline 5 & $160.1375-178.0625$ & 1 & 2 & -1 & 1 & 0.5 \\
\hline \multicolumn{2}{r|}{} & & & $X^{2}$ & 4 \\
\hline
\end{tabular}

Data pada Tabel 4 menunjukan nilai $\Sigma X^{2}$ yang didapatkan sebesar 4 . Hal ini menunjukkan pengujian untuk distribusi Log Pearson III dapat diterima karena nilai $\Sigma \mathrm{X}^{2}$ perhitungan lebih kecil dari $\Sigma X^{2}$ pada tabel uji Chi Kuadrat yang nilainya 9.404. Nilai yang digunakan merujuk pada Tabel 2 yaitu 147.19 nilai tersebut diambil karena menurut KEMENPU untuk analisis saluran drainase saluran pada daerah tangkapan air yang luasnya kurang dari $10 \mathrm{Ha}$ digunakan periode ulang 2 tahun. Curah hujan yang digunakan dalam simulasi sebesar $147.2 \mathrm{~mm}$ dan didistribusikan menggunakan distribusi hujan Tadashi Tanimoto. Tadashi Tanimoto pada tahun 1969 mengembangkan distribusi hujan jam-jaman yang dapat digunakan di Pulau Jawa (Triadmojo 2008).

\section{Kondisi Saluran Drainase}

Saluran drainase drainase pada sisi kanan Jalan Pemuda Bogor merupakan saluran primer yang terhubung dengan jaringan drainase sekitarnya dalam satu luasan sistem catchment area. Catchment area ditentukan berdasarkan pengamatan lansung dilapangan, yaitu dengan mengidentifikasi setiap saluran yang terhubung dengan saluran primer drainase kanan Jalan Pemuda Kota Bogor.

Kemudian berdasarkan pengamatan di dapatkan bahwa catchment area yang sistem drainase dibatasi oleh Jalan Dadali disebelah Utara, kemudian Jalan Jenderal Ahmad Yani di sebelah Timur dan Selatan. Dalam cathment area diketahui bahwa terdapat dua outlet dari jaringan drainase. Untuk menentukan outlet dari masing-masing saluran dilakukan identifikasi arah aliran dengan menganalisis kemiringan saluran yang diketahui dari pengukuran langsung dilapangan. Arah aliran pada jaringan drainase dapat dilihat dalam pemodelan jaringan drainase pada Gambar 2.

Berdasarkan

pengamatan didapatkan bahwa sistem jaringan drainase secara umum cukup baik karena terdapat saluran di setiap ruas jalan, namun terdapat beberapa saluran membutuhkan perawatan dan perbaikan seperti adanya sedimentasi dan kerusakan di bangunan drainase. Secara khusus kondisi saluran di sepanjang jalan pemuda lebih baik, tidak terdapat sedimentasi yang melibih $5 \mathrm{~cm}$ dan hanya ada sedikit kesudakan.

Sistem jaringan drainase perkotaan ini akan dimodelkan menggunakan software EPA SWMM 5.1, komponen yang diperlukan yaitu subcatchment, junction, conduit, dan outfall nodes. Setelah pemodelan didapatkan 61 subcatchment, 92 junction, 87 conduit, dan 2 outfall nodes dengan total luas catchment area 65 ha. Lokasi penelitian didominasi oleh bangunan perumahan dengan lahan hijau yang cukup, ditambah dengan area perkantoran dan pemerintahan, dan fasilitas umum.

Karakteristik subcatchment yang berbeda menghasilkan besar limpasan yang berbeda dan selanjutnya limpasan mengalir ke junction. Karakteristik subcatchment yang mempengaruhi diantaranya adalah luas subcatchment, \% 
impervious, dan \% pervious. Setiap juntiont dihubungkan oleh conduit atau saluran yang akan meneruskan aliran air yang diterima junction sebelumnya. Komponen lain yang digunakan yaitu rain gage sebagai pemberi informasi hujan rencana pada model jaringan drainase yang telah dibuat. Simulasi aliran dilakukan dengan menggunakan data curah hujan yang ditentukan dari analisis hidrologi curah hujan rencana. Data disimulasikan pada Time Series menggunakan pola distribusi hujan 8 jam. Berikut ini peta pemodelan jaringan drainase di daerah Jalan Pemuda Kota Bogor yang disajikan pada Gambar 3.

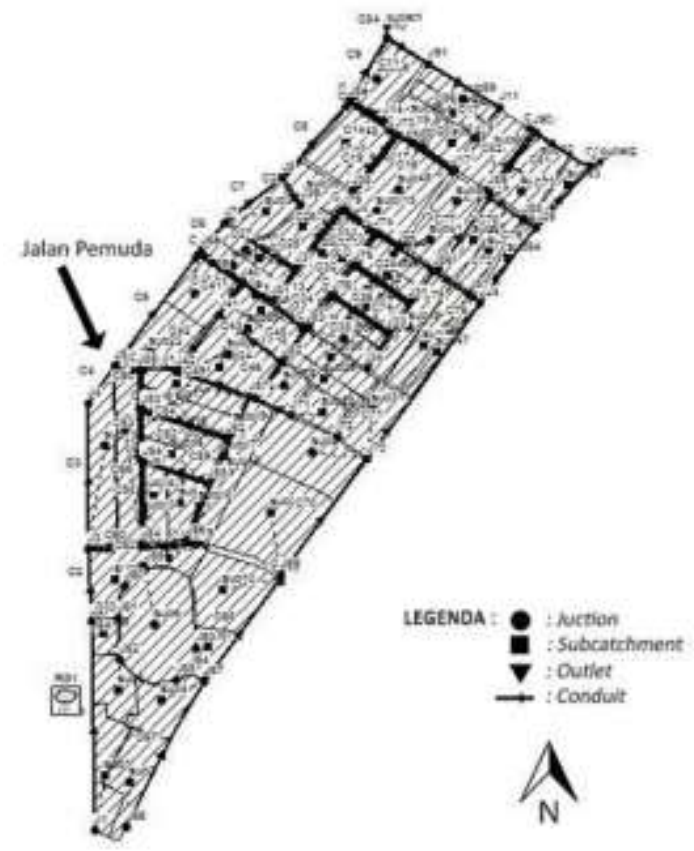

Gambar 3 Peta pemodelan jaringan drainase

\section{Evaluasi Saluran Drainase}

Simulasi jaringan drainase setelah disimulasikan menghasilkan kualitas yang cukup baik dengan nilai continuity error untuk limpasan permukaan dan penelusuran aliran masing-masing sebesar $-0.49 \%$ dan $0.01 \%$. Menurut Rossman (2004) jika kualitas simulasi mencapai angka $10 \%$, maka kualitasnya diragukan. Hasil simulasi dapat dilihat pada Gambar 4.

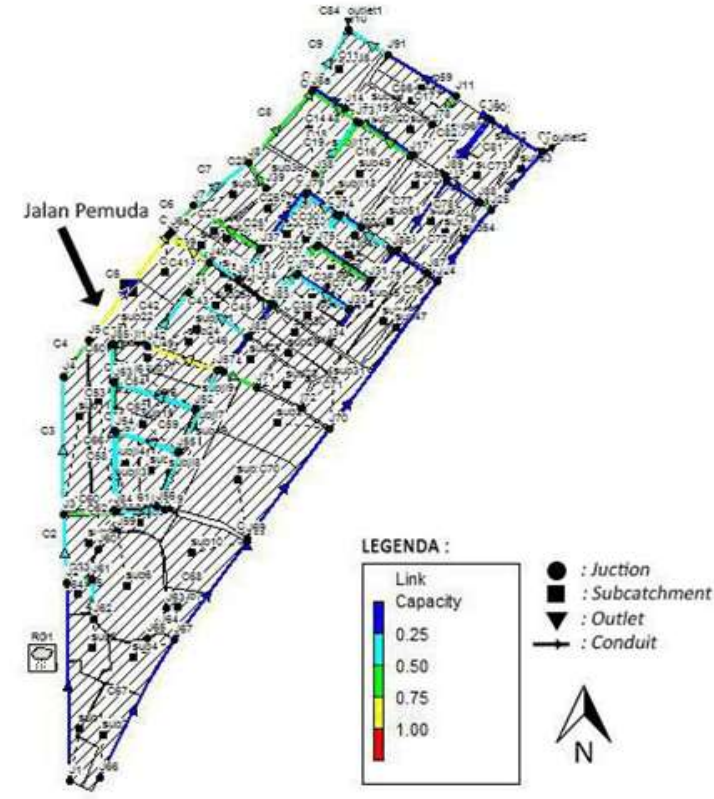

Gambar 4 Simulasi model pada gambar jam ke-2

Hasil simulasi jaringan drainase pada jam ke-2 menunjukan bahwa terdapat tiga saluran dengan indikator warna kuning yaitu saluran C5 yang berada di Jalan Pemuda Kota Bogor, saluran C40 dan saluran C49. Warna kuning pada saluran menunjukkan bahwa debit dan kedalaman limpasan hampir memenuhi atau tepat memenuhi saluran tersebut. Debit limpasan yang dihasilkan pada semua saluran bersikar $0.017-2.119$ $\mathrm{m}^{3} /$ detik. Debit yang mengalir pada saluran $\mathrm{C} 5, \mathrm{C} 40$ dan $\mathrm{C} 49$ berturut-turut adalah 1.49, 0.46 dan $0.23 \mathrm{~m}^{3} /$ det. Perbedaan hasil simulasi dengan keadaan dilapangan yang menunjukkan banjir di Jalan Pemuda disebabkan karena curah hujan maksimum harian yang terjadi lebih besar dari perkiraan analisis curah maksimum harian dalam periode ulang 5 tahun lebih.

Keadaan debit limpasan terhadap waktu dapat dilihat pada Gambar 5. 


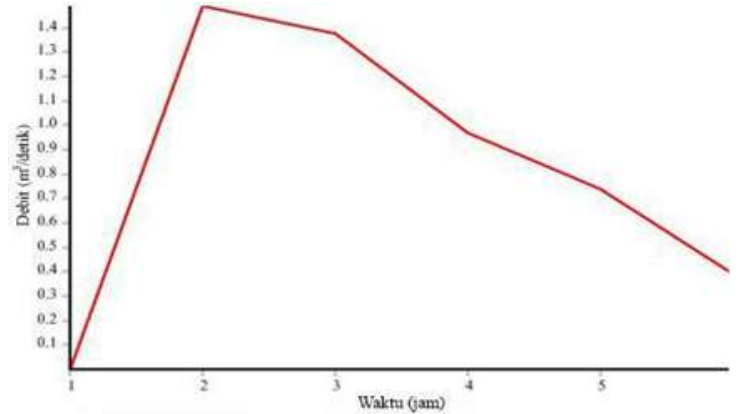

Gambar 5 Besar limpasan pada saluran C5 terhadap waktu

Debit rencana maksimum pada saluran C5 sebesar $1.49 \mathrm{~m}^{3} /$ detik terjadi pada jam ke-2 hujan. Kemudian debit rencana perlahan turun mencapai debit yang lebih rendah pada jam hujan berikutnya. Hal tersebut disebabkan karena dalam distribusi hujan 8 jam Tadashi Tanimoto yang digunakan, persentasi distribusi hujan tertinggi terjadi pada jam ke-1 kemudian jam ke-2 kemudian menurun hingga jam ke-8. Kedalaman limpasan atau profil aliran pada saluran C5 dapat dilihat pada Gambar 6.

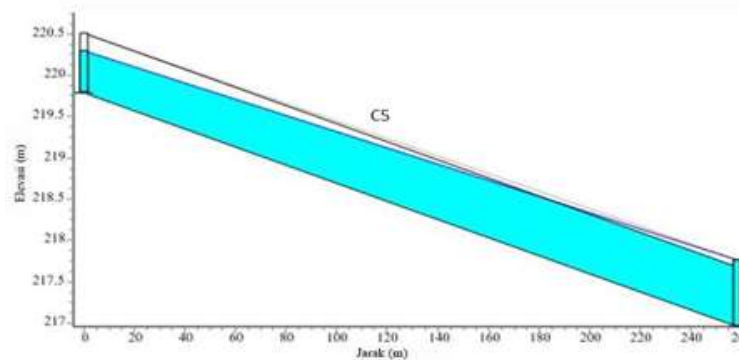

Gambar 6 Profil aliran saluran C5

Gambar 6 menunjukkan bahwa kondisi ketinggian limpasan atau profil aliran pada saluran C5 hampir memenuhi saluran. Ketinggian aliran yang mengalir pada saluran C5 adalah $0.61 \mathrm{~m}$ dengan kedalaman saluran C5 hasil pengukuran sebesar $0.72 \mathrm{~m}$. Sehingga selisih antara tinggi muka air dan tinggi saluran pada saluran C5 sebesar $0.11 \mathrm{~m}$ dengan kecepatan aliran sebesar $3.15 \mathrm{~m} /$ detik. Berdasarkan standar tinggi jagaan (freeboard) pada CIDA 1994 dalam
KEMENPU 2011 pada Tabel 6 dijelaskan bahwa standar freeboard untuk saluran yang terbuat dari beton dengan debit $0.5-$ $1.5 \mathrm{~m}^{3} / \mathrm{det}$ yaitu sebesar $0.2 \mathrm{~m}$. Berdasarkan hal tersebut, pada saluran C5 terjadi kekurangan tinggi jagaan Tinggi jagaan yang kurang dapat memperbesar kemungkinan terjadinya luapan pada saluran drainase. Sehingga dimensi saluran C5 perlu diperbesar.

Kedalaman aliran pada saluran C40 dan C49 yaitu 0.64 dan $0.35 \mathrm{~m}$ dengan selisih dari tinggi saluran sebesar 0.16 dan 0.05 m. Namun pada saluran C40 dan C49 tidak melanggar batas stadar tinggi jagaan dikarenakan debit yang mengalir dibawah $0.5 \mathrm{~m}^{3} /$ det. Akan tetapi pada dimensi saluran C40 dan C49 akan diperbesar pada pemodelan terindikasi berwrna kuning. Modifikasi terhadap dimensi saluran dilakukan dengan trial and error pada Tabel 5 dan 6 .

Tabel 5 Trial and error modifikasi dimensi saluran C5

\begin{tabular}{|c|c|c|c|c|c|c|}
\hline $\begin{array}{l}\text { Trial } \\
\text { and } \\
\text { error } \\
\end{array}$ & $\begin{array}{c}\text { Debit } \\
\text { Perhitungan } \\
\left(\mathrm{m}^{3} / \text { detik }\right)\end{array}$ & $\begin{array}{c}\text { Debit } \\
\text { Simulasi } \\
\left(\mathrm{m}^{3} / \mathrm{detik}\right) \\
\end{array}$ & $\begin{array}{c}\text { Lebar } \\
\text { saluran } \\
(\mathrm{m}) \\
\end{array}$ & $\begin{array}{c}\text { Kedalaman } \\
\text { Saluran } \\
(\mathrm{m})\end{array}$ & $\begin{array}{c}\text { Kedalaman } \\
\text { Simulasi } \\
(\mathrm{m})\end{array}$ & $\begin{array}{c}\text { Kecepatan } \\
\text { aliran } \\
\text { (m/detik) } \\
\end{array}$ \\
\hline 0 & 1.51 & 1.49 & 0.77 & 0.72 & 0.61 & 3.15 \\
\hline 1 & 1.77 & 1.49 & 0.77 & 0.82 & 0.66 & 2.91 \\
\hline 2 & 2.03 & 1.49 & 0.77 & 0.92 & 0.71 & 2.71 \\
\hline 3 & 2.30 & 1.49 & 0.77 & 1.02 & 0.76 & 2.53 \\
\hline \multicolumn{7}{|c|}{$\begin{array}{c}\text { Tabel } 6 \text { Trial and error modifikasi } \\
\text { dimensi saluran C49 }\end{array}$} \\
\hline $\begin{array}{l}\text { Trial } \\
\text { and } \\
\text { error } \\
\end{array}$ & $\begin{array}{c}\text { Debit } \\
\text { Perhitungan } \\
\left(\mathrm{m}^{3} / \text { detik }\right)\end{array}$ & $\begin{array}{c}\text { Debit } \\
\text { Simulasi } \\
\left(\mathrm{m}^{3} / \mathrm{detik}\right) \\
\end{array}$ & $\begin{array}{c}\text { Lebar } \\
\text { saluran } \\
(\mathrm{m}) \\
\end{array}$ & $\begin{array}{c}\text { Kedalaman } \\
\text { Saluran } \\
(\mathrm{m})\end{array}$ & $\begin{array}{c}\text { Kedalaman } \\
\text { Simulasi } \\
(\mathrm{m})\end{array}$ & $\begin{array}{c}\text { Kecepatan } \\
\text { aliran } \\
(\mathrm{m} / \text { detik }) \\
\end{array}$ \\
\hline 0 & 0.29 & 0.23 & 0.59 & 0.4 & 0.35 & 1.09 \\
\hline 1 & & 0.23 & 0.59 & 0.45 & 0.37 & 1.05 \\
\hline 2 & 0.39 & 0.23 & 0.59 & 0.5 & 0.37 & 1.04 \\
\hline
\end{tabular}

Perubahan dimensi saluran drainase dilakukan di dua saluran yaitu saluran C5 dan C49, dan tidak dilakukan perubahan pada saluran $\mathrm{C} 40$. Hal itu disebabkan karena setelah dilakukan perubahan pada saluran C5 berdampak 
pada saluran C40 dengan perubahan indikator warna dari warna kuning menjadi hijau. Perubahan dimensi saluran akan berdampak pada perubahan slope, debit maksimum saluran, kecepatan aliran dan kedalaman aliran. Seperti pada saluran C5 kedalaman saluran yang semakin besar berdampak pada perubahan slope pada saluran sebelumnya $\mathrm{C} 4$ dan setelahnya C5a. Slope pada saluran C4 semakin besar sehngga kecepatan aliran semakin besar sebaliknya pada saluran C5a mengalami penurunan nilai slope sehingga kecepatan alirannya berkurang.

Hasil akhir perubahan didapatkan bahwa dimensi saluran C5 adalah $1.02 \mathrm{x}$ $0.77 \mathrm{~m}$ dan dimensi saluran C49 adalah $0.5 \times 0.59 \mathrm{~m}$. Sehingga tinggi jagaan pada saluran C5 didapatkan sebesar $24 \mathrm{~cm}$ dengan kecepatan aliran $2.53 \mathrm{~m} /$ detik, sesuai dengan standar CIDA 1994 dalam KEMENPU 2011. Kemudian biaya perbaikan dimensi saluran berdasarkan perhitungan sebesar Rp 20,328,000 yang disajikan pada Tabel 9. Dimensi saluran yang baru kemudian disimulasikan ulang dan hasilnya seperti pada Gambar 7.

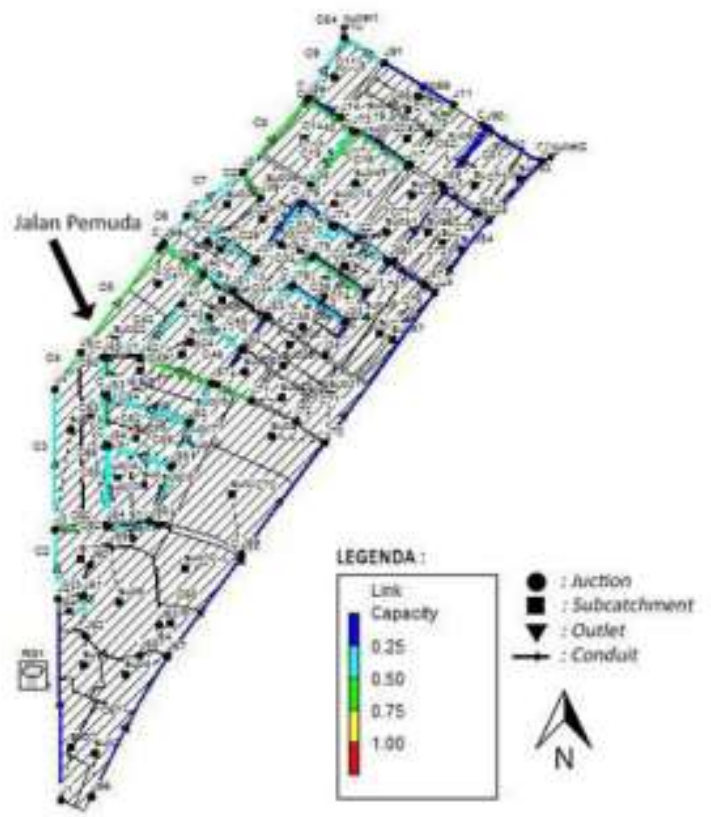

Gambar 7 Simulasi model setelah modifikasi pada jam ke-2
Berdasarkan Gambar 7 dapat dilihat bahwa indikator warna saluran C5, C40 dan C49 yang sebelumnya berwarna kuning, setelah dilakukan modifikasi terhadap dimensi saluran C5 dan C49 maka indikator warnanya berubah menjadi hijau. Besar daya tampung debit limpasan pada saluran C5, C40 dan C49 berturutturut sebesar 2.3, 1.18, dan $0.39 \mathrm{~m} 3 /$ detik. Kemudian profil saluran $\mathrm{C} 5$ setelah dimodifikasi disajikan pada Gambar 8.

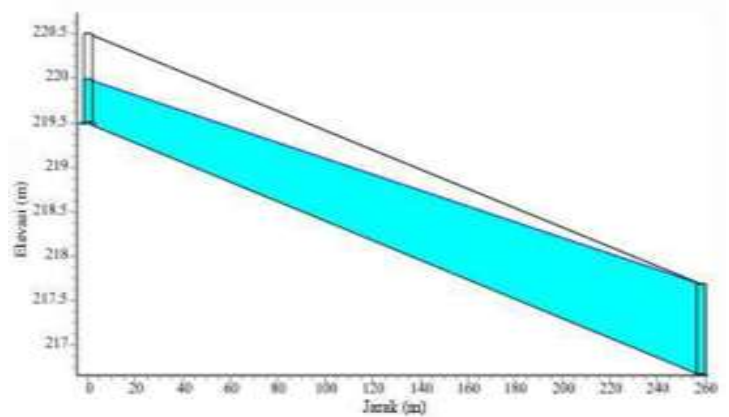

Gambar 8 Simulasi profil saluran C5 setelah dimodifikasi

Gambar 8 menunjukkan ketinggian limpasan hasil simulasi setelah dimensi saluran diperbesar. Kedalaman saluran C5 setelah diperbesar menjadi $0.87 \mathrm{~m}$, menghasilkan kedalaman limpasan sebesar $0.63 \mathrm{~m}$. Hal itu ditandai dengan indikasi warna hijau di saluran C5 pada hasil simulasi Gambar 7. Dengan demikian simulasi yang dilakukan untuk memperbaiki saluran drainase dikatakan berhasil.

\section{KESIMPULAN}

Sistem drainase di daerah Jalan Pemuda, Kota Bogor terdiri dari saluran terbuka dengan bentuk penampang saluran persegi dengan kontruksi beton dan memiliki catchment area sebesar \pm 65 ha. Konstruksi saluran menggunakan beton dengan elevasi saluran $194-230 \mathrm{~m}$. Terdapat 61 subcatchment, 92 junction, 87 conduit, dan 2 outfall nodes. 
Total debit puncak limpasan hasil simulasi diperoleh sekitar $0.017-2.119$ $\mathrm{m}^{3} /$ det. Saluran drainase di sepanjang Jalan pemuda, Kota Bogor yang hampir memenuhi kapasitas limpasan berada di saluran C5, C40 dan C49 yaitu dengan debit limpasan berturut-turut 1.49, 0.46, dan $0.23 \mathrm{~m}^{3} /$ det pada saat curah hujan maksimum harian mencapai $147.19 \mathrm{~mm}$. Dimensi saluran perlu diperbesar yaitu saluran C5 dari $0.72 \mathrm{~m}$ x $0.77 \mathrm{~m}$ menjadi $1.02 \mathrm{~m}$ x $0.77 \mathrm{~m}$ dan saluran C49 dari 0.72 $\mathrm{m} \times 0.77 \mathrm{~m}$ menjadi $0.5 \mathrm{~m} \times 0.59 \mathrm{~m}$ dengan biaya $\operatorname{Rp} 20,328,000$.

\section{DAFTAR PUSTAKA}

Anwar, Pudoyono, Ruslin M, Suharyanto A, Suroso, Wicaksono DH. 2014. Evaluasi dan Perencanaan Ulang Saluran Drainase pada Kawasan Perumahan Sawojajar Kecamatan Kedungkandang Kota Malang. Jurnal Rekayasa Sipil. 8(3): 207

Chow VT. 1997. Hidraulika Saluran Terbuka (terjemahan). Jakarta (ID) : Penerbit Erlangga

[DepPPW] Departemen Pemukiman dan Prasarana Wilayah. 2001. Kegiatan Operasional Jalan Tol. Keputusan Menteri Pemukiman dan Prasarana Wilayah No. 543/KPTS/M/2001. Jakarta (ID): Departemen Pemukiman dan Prasarana Wilayah.

[DepPPW] Departemen Pemukiman dan Prasarana Wilayah. 2002. Modul Pelatihan Manajemen Prasarana dan Sarana Perkotaan. Jakarta (ID): Departemen Pemukiman dan Prasarana Wilayah.

[DepPU] Departemen Pekerjaan Umum. 1989. Metode Perhitungan Debit Banjir. Edisi Pertama. Bandung (ID): Yayasan Lembaga Penyelidikan Bangunan.
Dewi AK, Setiawan A, Saido AP. 2014. Evaluasi Sistem Saluran Drainase di Ruas Jalan Solo Sragen Kabupaten Karanganyar. Jurnal Matriks Teknik Sipil. 2(1):170176.

Fadhlillah ML. 2014. Evaluasi Saluran Drainase di Bogor Nirwana Residence Dengan Model EPA SWMM 5.1 [skripsi]. Bogor (ID): Institut Pertanian Bogor.

Farizi D. 2015. Analisis dan Evaluasi Saluran Drainase pada Kawasan Perumnas Talang Kelapa di SubDAS Lambidaro Kota Palembang. Jurnal Teknik Sipil dan Lingkungan. 3(1):755-765

Hasmar HHA. 2011. Drainase Terapan. Yogyakarta (ID): UII Press.

Irianto G. 2003. Banjir dan Kekeringan. Bogor (ID): Universal Pustaka Media. Isfandari DT, Ilmiaty RS, Sirk Baitullah AM. 2014. Analisis Sistem Drainase di Kawasan Pemukiman pada Sub DAS Aur Palembang (Studi Kasus :Pemukiman 9/10 ULU). Jurnal Teknik Sipil dan Lingkungan. 2(1): $131-136$.

Jang JH, Park CK, Park HS. 2006. Analysis of the effect of sewer system on urban stream using PCSWMM based on GIS. Jurnal Korean Soc. Water Quality. 22 (6) : 982-990.

[KemenPU] Kementerian Pekerjaan Umum. 2011. Materi Bidang Drainase. Jakarta (ID): Kementerian Pekerjaan Umum.

Long A R, Ioannides A M. 2007. Drainage Evaluation at the U.S. Journal of Transportation Engineering. 1(1): 133

Luciana RF, Edijatno, Sofia F. 2013. Analisa Sistem Drainase Saluran Kupang Jaya akibat Pembangunan Apartemen Puncak Bukit Golf di Kota Surabaya. Jurnal 
Teknik Pomits. 1(1):1-5.

Maryono A. 2004. Banjir,

Kekeringan dan Lingkungan.

Yogyakarta (ID). Universitas

Gadjah Mada. Nasution A. 2009.

Analisis dan Desain Struktur

Beton Bertulang. Bandung (ID): ITB.

Pediano D, Hadiani R, Suyanto. 2014. Penelusuran Banjir di DAS Temon dengan Metode MuskingumCunge Menggunakan HydroCAD. Jurnal Matriks Teknik Sipil. 2(4):718-726

Purba MP. 2009. Besaran Aliran Permukaan (Run-off) pada Berbagai tipe Kelerengan di Bawah Tegakan Eucalyptus spp. (Studi Kasus di HPHTI PT.Toba Pulp Lestari, Tbk. Sektor Aek Nauli) [Skripsi]. Medan(ID): Universitas Sumatera Utara.

Rossman L. 2004. Storm Water Management Model User's Manual Version 5.0. Cincinnati (US) : EPA United Stated Environmental Agency.

Soemarto CD. 1995. Hidrologi Teknik. Edisi Kedua. Jakarta (ID): Erlangga.

Sukarto H. 1999. Drainase Perkotaan. Jakarta (ID): Mediatama Saptakarya.

Suripin. 2004. Sistem Drainase Perkotaan yang Berkelanjutan. Yogyakarta (ID): ANDI.

Suroso, Suharyanto A, Anwar MR, Wicaksono DH. 2014. Evaluasi dan Perencanaan Ulang Saluran Drainase Pada Kawasan Perumahan Sawojajar Kecamatan Kedungkandang Kota Malang. Jurnal Rekayasa Sipil. 8(3): 209210

Tanimoto T. 1969. Revised and Enlarge Edition of the Hourly Rainfall Analysis in Java. Bandung (ID): Penerbit ITB
Tim Penyusun. 2010. Pedoman Penulisan Karya Ilmiah. Bogor (ID): IPB Press

Triatmodjo B. 2008. Hidrologi Terapan. Yogyakarta (ID): Beta Offset

Triatmodjo B. 2010. Hidraulika II. Yogyakarta (ID): Beta Offset

Wibowo A, Widyatmoko MY, Darsono S, Sugiyanto.2014. Perencanaan saluran drainase kawasan oasis PT. Djarum Kudus di Kabupaten Kudus. Jurnal Karya Teknik Sipil. 3(1): $79-86$

Widodo E, Ningrum D. 2015. Evaluasi Sistem Jaringan Drainase Permukiman Soekarno Hatta Kota Malang dan Penanganannya. Jurnal Ilmu-Ilmu Teknik. 11(3):6-8

Wismarini T D, Ningsih DHU. 2010. Analisis Sistem Drainase Kota Semarang Berbasis Sistem Informasi Geografi dalam Membantu Pengambilan Keputusan bagi Penanganan Banjir. Jurnal Teknologi Informasi. 15(1):71-74 